\title{
Minimized Low-Profile Wideband Antennas Using High Impedance Surface
}

\author{
Yizhu Shen \\ State Key Laboratory of Millimeter Waves, Southeast University, Nanjing 210096, China \\ Correspondence should be addressed to Yizhu Shen; yizhu.shen@seu.edu.cn
}

Received 5 April 2017; Revised 19 June 2017; Accepted 25 July 2017; Published 19 September 2017

Academic Editor: Xianming Qing

Copyright (C) 2017 Yizhu Shen. This is an open access article distributed under the Creative Commons Attribution License, which permits unrestricted use, distribution, and reproduction in any medium, provided the original work is properly cited.

\begin{abstract}
This paper proposes minimized low-profile wideband antenna by employing high impedance surface (HIS), for wireless application scenarios at radio frequency, microwave, and even terahertz. To validate this concept with low cost and easy measurement, two prototypes at radio frequency are fabricated and tested. Firstly, antenna with dielectric-substrate reflector is proposed and analyzed and $4 \times 6 \mathrm{HIS}$ array is employed to minimize the antenna size to $0.57 \lambda_{L} \times 0.86 \lambda_{L} \times 0.078 \lambda_{L}$, while maintaining antenna performances such as bandwidth, gain, and directive radiation. Secondly, a substrate-less HIS is proposed to improve the antenna bandwidth from $36 \%$ to $52 \%$ and also reduces the antenna weight by $72 \%$.
\end{abstract}

\section{Introduction}

Antenna with low-profile and high directive gain has been widely researched, and the demand in practical applications is increasing $[1,2]$. Generally, there are two methods to realize it. One way is to add electromagnetic absorber in the backside cavity of antenna $[3,4]$. However, this will reduce the efficiency of the antenna, and there is a tradeoff among the cavity thickness, bandwidth, and the antenna gain. The other common approach is employing the metallic ground as a reflector $[5,6]$. Nevertheless, because the reflection of metallic ground is out-of-phase, a separation gap about quarter-wavelength between the antenna and the reflector is required, to generate the constructive interference between the incident and reflected waves. This quarter-wavelength gap results in two problems, that is, narrow bandwidth and bulky size. To alleviate these problems, electromagnetic bandgap (EBG) structure, which is also known as metamaterial, photonic bandgap (PBG), or hard/soft surfaces, is proposed by changing the surface characteristics on the ground [7-10].

Among these EBG structures, high impedance surface (HIS) has demonstrated many advantages in low-profile antenna designs. It was invented by Sievenpiper et al. in [1], to emulate a perfect magnetic conductor (PMC). Compared to conventional perfect electric conductor (PEC), PMC generates an in-phase reflection phase response, which enables locating the antenna closer to the reflector ground. It is worth mentioning that HIS only achieves the pure in-phase response at the resonant frequency, while its phase response decreases from $180^{\circ}$ to $-180^{\circ}$ with increased frequencies. Therefore, the pseudo-PMC effect of HIS is defined as bandgap range of $0^{\circ} \pm 90^{\circ}$.

Using HIS as a reflector, a lot of low-profile antennas have been reported [11-16]. A planar folded dipole on via-less dog bone-shaped HIS array is presented in [11], achieving a measured impedance bandwidth of $6 \%$ and a boresight gain of $6.4 \mathrm{dBi}$. A planar antenna with extremely low profile $\left(\lambda_{0} / 74\right)$ is proposed in [12], but it is narrowband $(<1 \%)$ resonant only at a single frequency. By inserting via only at reflector edges, while the center part is via-less, a hybrid HIS is proposed in [13], which significantly alleviates antenna beam distortion and reduces side lobe level. Low-profile bowtie antennas are published in [14-16] with wide bandwidth and small physical thickness. However, the electrical thickness is still large.

This paper presents HIS based antennas with minimized electrical size and low profile as well as wide bandwidth and directive radiation patterns. Firstly, a dielectric-substrate HIS is employed as the ground reflector of a bow tie antenna, and 
the effect of the reflector size to the antenna performance is investigated. In this way, a minimized ground reflector is realized. Secondly, to improve the bandwidth, an air-gap HIS is designed without bulky dielectric substrate.

This paper is organized as follows. Section 2 introduces the operating principle of low-profile bow tie antenna on top of a dielectric-substrate HIS array. The minimization of HIS ground size and its effect to the antenna performance are analyzed. In the following, Section 3 presents a compact antenna design based on substrate-less HIS. Section 4 describes the measurement verifications of these two designs and also compares the proposed methods with other state-ofthe-art designs. Finally, Section 5 concludes this paper.

\section{Antenna with Dielectric-Substrate HIS}

2.1. Dielectric-Substrate HIS. HIS is a class of periodic structure, of which the cell size is much smaller than one wavelength. Many forms of periodic structures were studied in detail for its surface wave guiding abilities between 1950s and 1960s.

As shown in Figure 1(a), the HIS structure invented by Sievenpiper et al. [1] is in the form of grounded top-hat, that is, a common flat metallic ground at the bottom and periodical metallic patches on the top. They are connected to each other with vertical metal via. The operating principle of HIS can be explained using an equivalent parallel $L C$ filter: the capacitance is introduced by the gap between two adjacent patches, and the inductance is generated in the loop which goes through vias between the two patches. Therefore, their analytical formula can be derived and listed as follows [1]:

$$
\begin{aligned}
& C=\frac{w \varepsilon_{0}\left(\varepsilon_{r 1}+\varepsilon_{r 2}\right)}{\pi} \cosh ^{-1}\left(\frac{a}{g}\right), \\
& L=\mu_{0} h,
\end{aligned}
$$

where $a, g, w$, and $h$ are width/thickness marked in Figure $1(\mathrm{a}), \varepsilon_{0}$ and $\mu_{0}$ are the free-space permittivity and permeability, respectively, and $\varepsilon_{r 1}$ and $\varepsilon_{r 2}$ are the relative dielectric constant of materials surrounded at two sides of HIS top patches. The resonant frequency, surface input impedance, and bandwidth can be derived from this parallel $L C$ filter as follows [1]:

$$
\begin{aligned}
f_{c} & =\frac{1}{2 \pi \sqrt{L C}}, \\
Z_{s} & =(j \omega L) / /\left(\frac{1}{j \omega C}\right)=\frac{j \omega L}{1-\omega^{2} L C}, \\
\text { B.W. } & =\frac{\Delta \omega}{\omega_{0}}=\frac{\sqrt{L / C}}{\eta} .
\end{aligned}
$$

Based on this, the HIS unit cell proposed in this paper is shown in Figure 1(b). It is based on air and Teflon substrate $\left(\varepsilon_{r 1}=1\right.$ and $\left.\varepsilon_{r 2}=2.1\right)$. Brass square patches with a thickness of $h_{1}=0.5 \mathrm{~mm}$ and aluminum with a thickness $h_{2}=6 \mathrm{~mm}$ are located on the top and bottom layers, respectively. M10 metallic screws with diameter $r=10 \mathrm{~mm}$ are used as shorting vias.

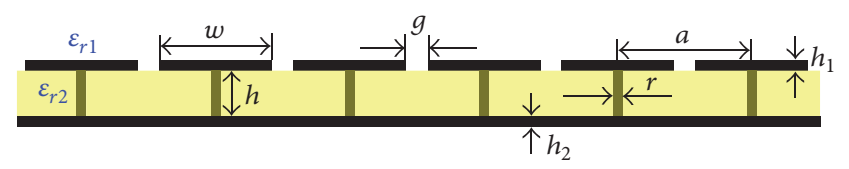

(a)

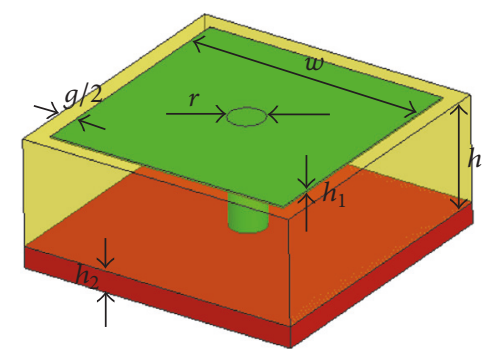

(b)

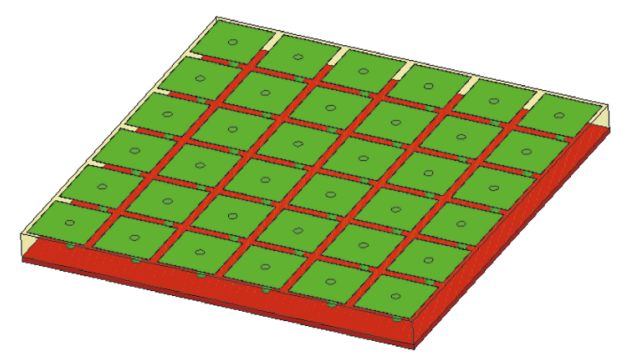

(c)

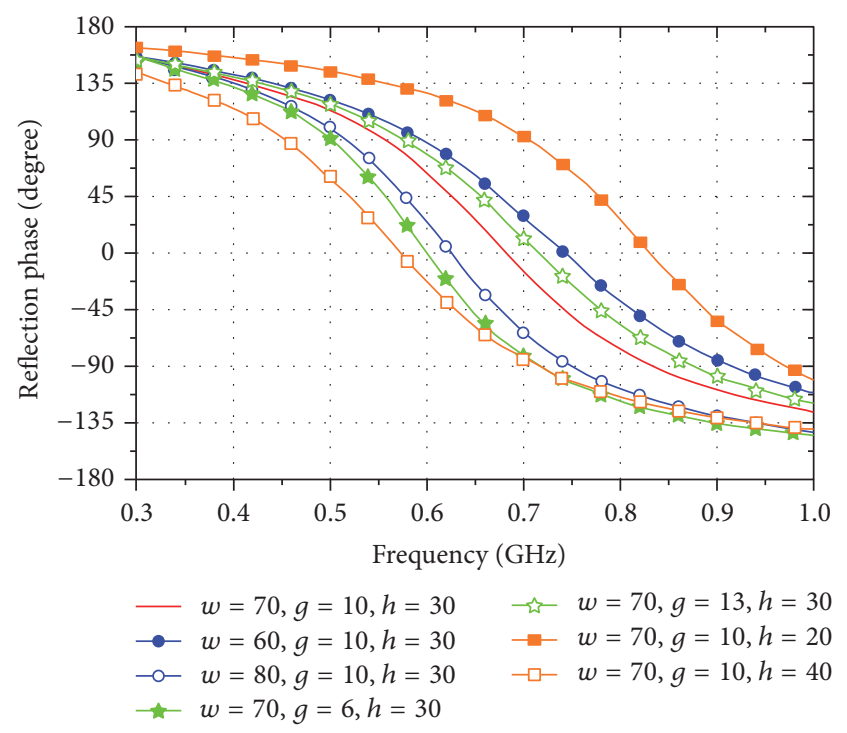

(d)

FIGURE 1: The proposed HIS structure: (a) HIS cross-sectional view, (b) the unit cell, (c) proposed $6 \times 6$ HIS array, and (d) reflection phase response.

Figure 1(d) shows the HIS reflection phase response, derived from the full-wave analysis of the unit cell with periodic boundary conditions. By fixing $h_{1}, h_{2}$ and $r$, the other three key parameters $(w, g$, and $h)$ are studied. As summarized in Table 1, when the HIS patch width $w$ increases, the bandgap becomes narrower and the resonant frequency shifts to lower frequency. On the contrary, when the patch 


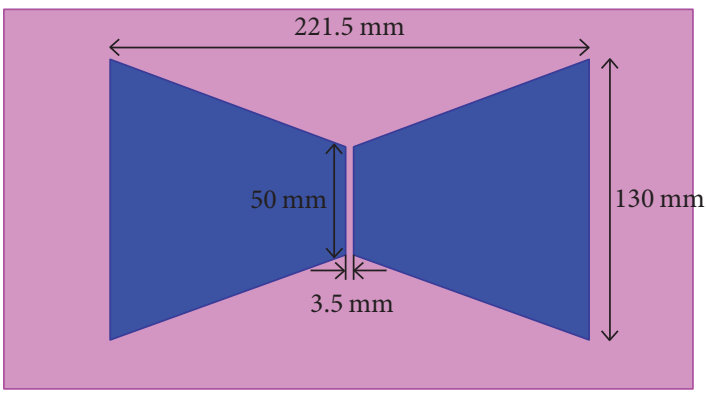

(a)

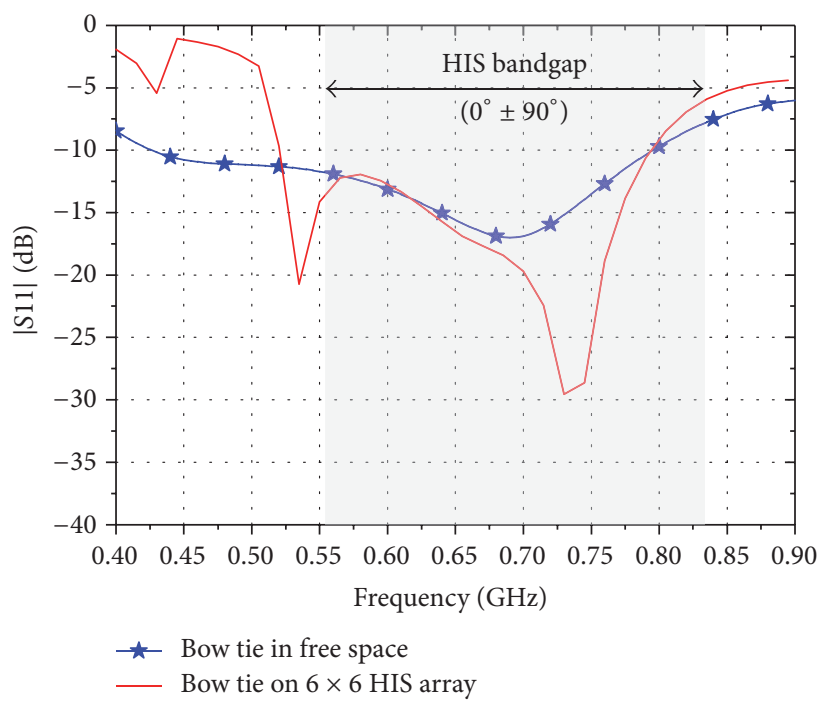

(c)

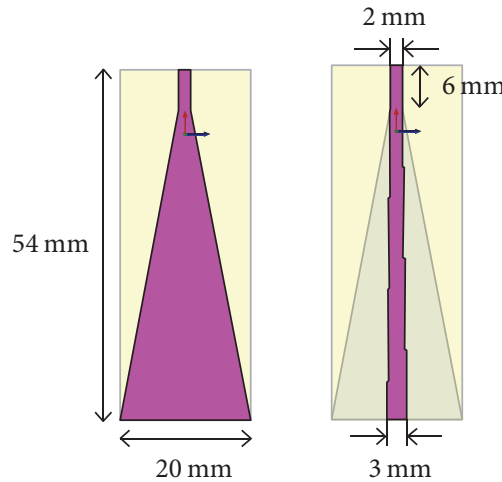

(b)

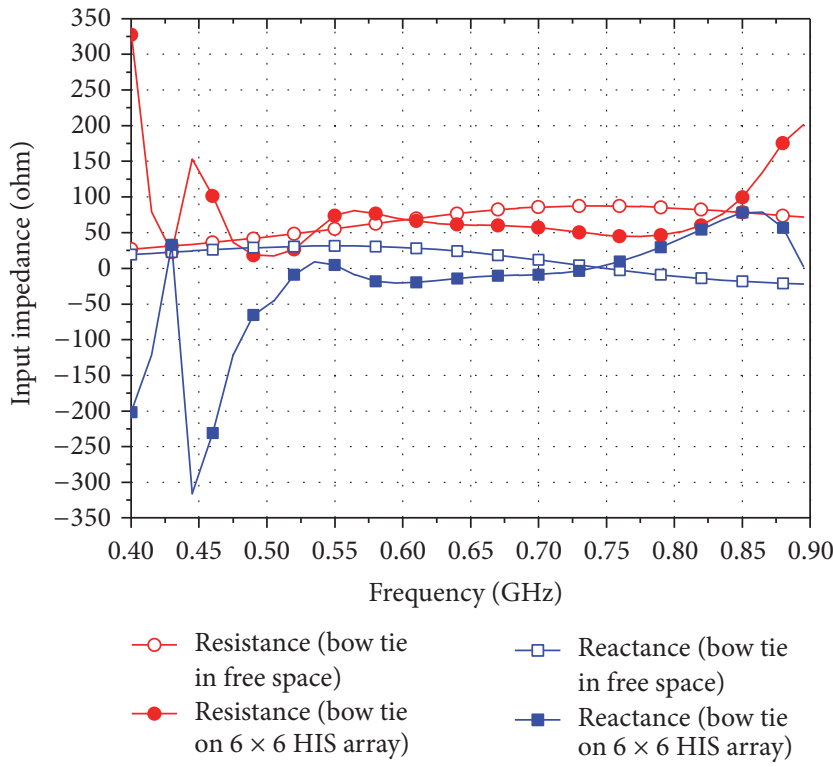

(d)

Figure 2: The bow tie antenna: (a) bow tie arms, (b) balun, (c) $\left|S_{11}\right|$ curves, and (d) input impedance.

TABLE 1: Parameter study of HIS unit cell.

\begin{tabular}{lccc}
\hline $\begin{array}{l}\text { HIS } \\
\text { (unit: } \mathbf{m m})\end{array}$ & $\begin{array}{c}\text { Bandgap } \\
\left(0 \pm 90^{\circ}\right)\end{array}$ & Bandwidth & $\begin{array}{c}\text { Resonant } \\
\text { frequency }\end{array}$ \\
\hline $\mathbf{w}=\mathbf{7 0}, \mathbf{g}=\mathbf{1 0}, \mathbf{h}=\mathbf{3 0}$ & $\mathbf{( 0 . 5 6 - 0 . 8 3 )} \mathbf{G H z}$ & $\mathbf{3 9} \%$ & $\mathbf{0 . 6 8 ~ G H z}$ \\
$\mathbf{w}=\mathbf{6 0}, \boldsymbol{g}=10, h=30$ & $(0.59-0.92) \mathrm{GHz}$ & $44 \%$ & $0.74 \mathrm{GHz}$ \\
$\mathbf{w}=\mathbf{8 0}, \boldsymbol{g}=10, h=30$ & $(0.52-0.75) \mathrm{GHz}$ & $36 \%$ & $0.625 \mathrm{GHz}$ \\
$w=70, \mathbf{g}=\mathbf{6}, h=30$ & $(0.50-0.72) \mathrm{GHz}$ & $36 \%$ & $0.6 \mathrm{GHz}$ \\
$w=70, \mathbf{g}=\mathbf{1 3}, h=30$ & $(0.58-0.88) \mathrm{GHz}$ & $41 \%$ & $0.715 \mathrm{GHz}$ \\
$w=70, \boldsymbol{g}=10, \mathbf{h}=\mathbf{2 0}$ & $(0.71-0.97) \mathrm{GHz}$ & $31 \%$ & $0.83 \mathrm{GHz}$ \\
$w=70, \boldsymbol{g}=10, \mathbf{h}=\mathbf{4 0}$ & $(0.45-0.71) \mathrm{GHz}$ & $45 \%$ & $0.57 \mathrm{GHz}$ \\
\hline
\end{tabular}

gap $g$ increases, the bandgap becomes wider and the resonant frequency shifts to higher frequency. Additionally, thicker substrate $h$ results in larger bandwidth, whereas the resonant frequency shifts to lower band. Therefore, after a tradeoff consideration, the HIS parameters are chosen as the second row in Table 1: $w=70 \mathrm{~mm}, g=10 \mathrm{~mm}$, and $h=30 \mathrm{~mm}$, to achieve an antenna with minimized size as well as large bandwidth.

Meanwhile, employing (1)-(2), the theoretical equivalent circuit model of the HIS is calculated as $C=1.75 \mathrm{pF}, L=$ $37.7 \mathrm{nH}$, and $f_{c}=0.62 \mathrm{GHz}$, which is slightly lower than wave-full simulated $0.68 \mathrm{GHz}$. It is mainly because some parameters such as $h_{1}, h_{2}$, and $r$ are considered as ideal in the theoretical analysis. Finally, employing the unit cell, a $6 \times$ 6 HIS array is formed in Figure 1(c), with overall size of 480 $\times 480 \times 36.5 \mathrm{~mm}^{3}$.

2.2. Wideband Bowtie Antenna. A bow tie antenna in free space is designed to cover the wide bandgap of the abovementioned HIS. As shown in Figure 2(a), the two bow tie arms are etched on top of a FR-4 substrate, with dielectric constant of 4.4 and thickness of $1.6 \mathrm{~mm}$. The length and width of the bow tie antenna are $221.5 \mathrm{~mm}$ and $130 \mathrm{~mm}$, respectively. There is no ground at the bottom side of FR-4.

To feed the differential bow tie antenna, a balun is designed as shown in Figure 2(b). This balun is etched on 


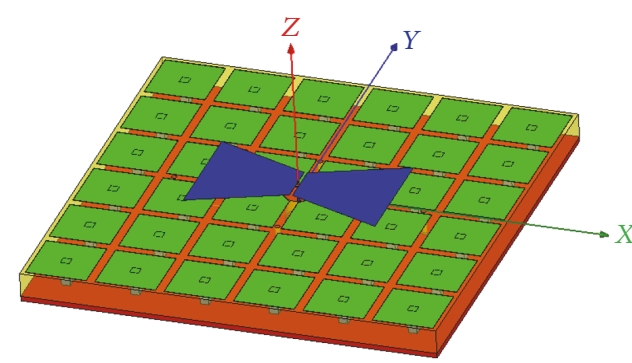

(a)

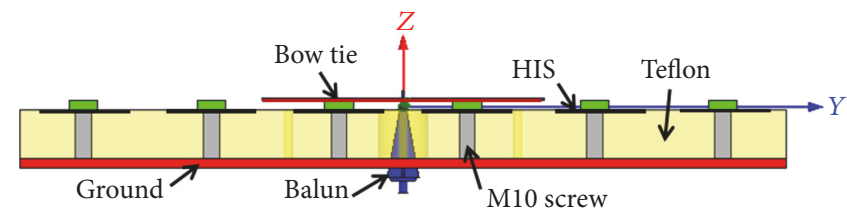

(b)

Figure 3: Low-profile bow tie antenna: (a) 3D view and (b) cross-sectional view.

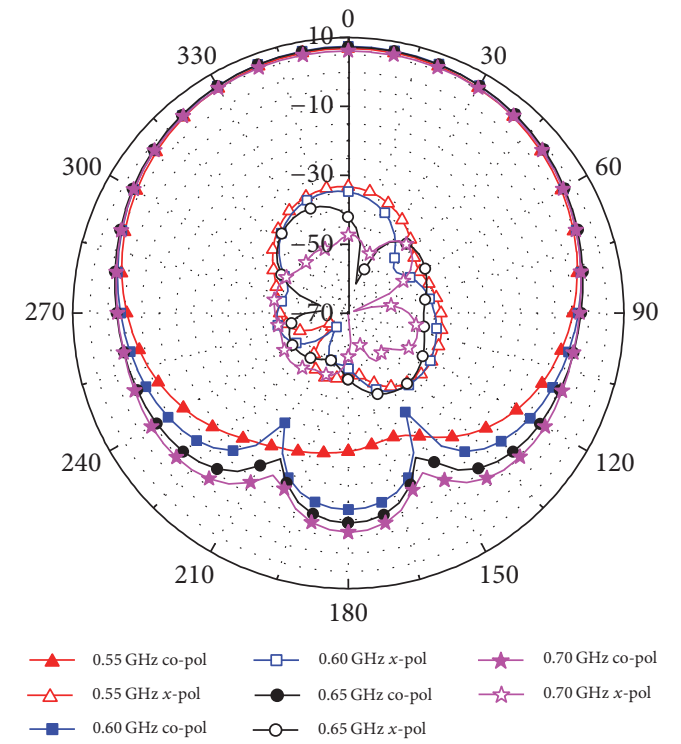

(a)

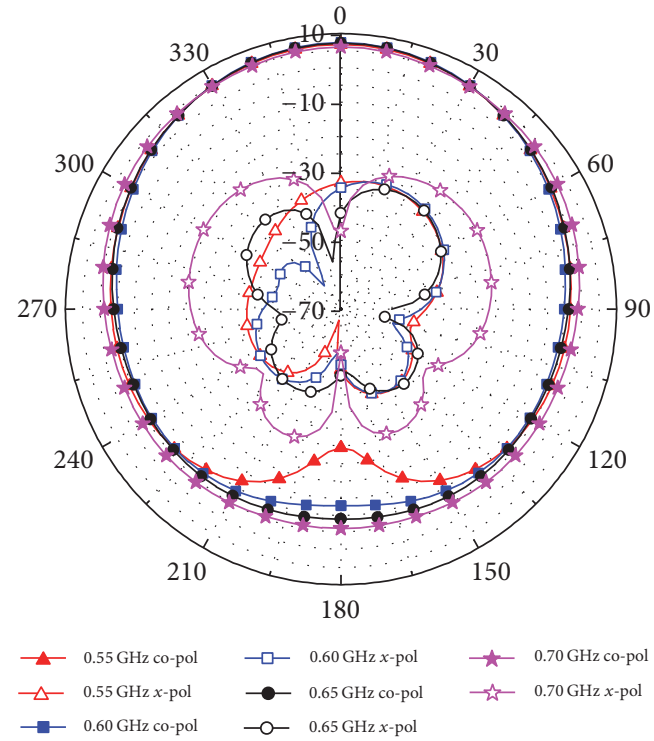

(b)

FIGURE 4: The radiation patterns of the bow tie antenna on $6 \times 6$ HIS array: (a) E-plane $(z-x)$ and (b) $H$-plane $(z-y)$.

double sides of a FR-4 substrate. It transfers from $50 \Omega$ microstrip (line width of $3 \mathrm{~mm}$ ) to stripline (line width of $2 \mathrm{~mm}$ ). The balun has a total length of $54 \mathrm{~mm}$ and vertically feeds the two bowtie arms.

As shown in Figure 2(c), the $10 \mathrm{~dB}$ return-loss bandwidth of this bow tie antenna in free space is $0.42-0.79 \mathrm{GHz}$, with the input impedance shown in Figure 2(d).

In the following, the $6 \times 6$ HIS array in Section 2.1 is employed as the ground reflector of this bow tie antenna, as shown in Figure 3(a). The cross-sectional view in Figure 3(b) shows that there is no metal ground in the bow tie antenna in Figure 2(a); it thus can be directly located on top of the M10 screw head with height of $5.5 \mathrm{~mm}$. In addition, a hole is excavated in the center part of both Teflon substrate and ground, to insert the balun to vertically feed the bowtie antenna.

$\left|S_{11}\right|$ curves of this bow tie antenna with $6 \times 6$ HIS array are shown in Figure 2(c), and the HIS unit cell bandgap derived in Figure 1 is also given in Figure 2(c). Compared to bow tie in free space, the proposed antenna with HIS reflector covers $0.52-0.795 \mathrm{GHz}$ or $42 \%$ referred to the center frequency of $0.658 \mathrm{GHz}$. The impact of HIS is highlighted by the HIS bandgap. The working bandwidth shifts slightly to the lower frequency due to the mutual coupling between bow tie and reflector, and the bandgap strongly affects the matching bandwidth of antenna. The proposed antenna features a physical size of $480 \times 480 \times 43.6 \mathrm{~mm}^{3}$, that is, a very small electrical size of $0.83 \lambda_{L} \times 0.83 \lambda_{L} \times 0.076 \lambda_{L}$ (where $f_{L}=$ $0.52 \mathrm{GHz}$ ).

In addition, the simulated radiation patterns of $E$-plane $(z-x)$ and $H$-plane $(z-y)$ at four selected frequency points are given in Figures 4(a) and 4(b). Directive radiation patterns are observed with maximum radiation about $7.6 \mathrm{dBi}$ in the $+z$ direction $\left(\theta=0^{\circ}\right)$, and the surface wave is highly suppressed in the $x-y$ plane $\left(\right.$ when $\left.\theta= \pm 90^{\circ}\right)$.

2.3. HIS Reflector Minimization. Figure 5 plots the surface current distribution on this $6 \times 6$ HIS array. It is observed that the current is mainly concentrated in the center area of the reflector, instead of spreading to the edges, showing that the surface wave propagation is highly suppressed by HIS. Additionally, there is little current distribution at the 


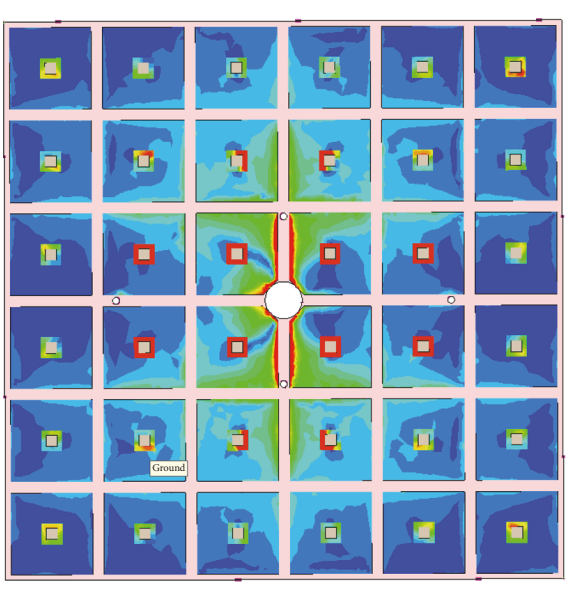

(a)

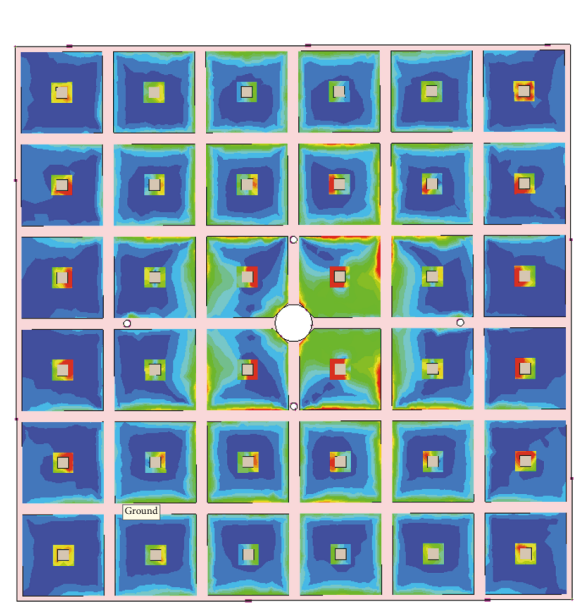

Jsurf (A_per_m)

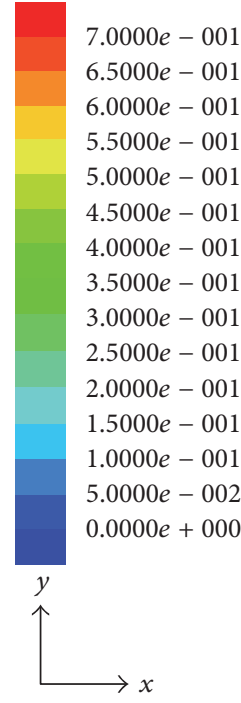

(c)

Jsurf (A_per_m)

$7.0000 e-001$

$6.5000 e-001$

$6.0000 e-001$

$5.5000 e-001$

$5.0000 e-001$

$4.5000 e-001$

$4.0000 e-001$

$3.5000 e-001$

$3.0000 e-001$

$2.5000 e-001$

$2.0000 e-001$

$1.5000 e-001$

$1.0000 e-001$

$5.0000 e-002$

$0.0000 e+000$

$y$

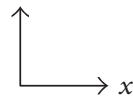

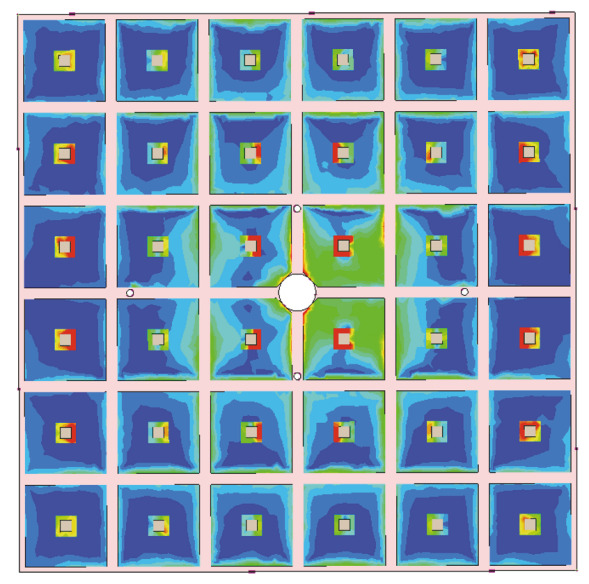

Jsurf (A_per_m)

$7.0000 e-001$

$6.5000 e-001$

$6.0000 e-001$

$5.5000 e-001$

$5.0000 e-001$

$4.5000 e-001$

$4.0000 e-001$

$3.5000 e-001$

$3.0000 e-001$

$2.5000 e-001$

$2.0000 e-001$

$1.5000 e-001$

$1.0000 e-001$

$5.0000 e-002$

$0.0000 e+000$
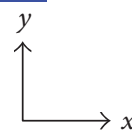

(b)

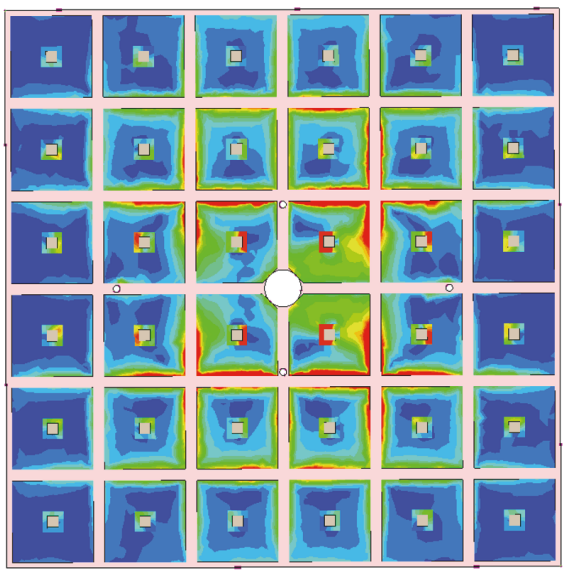

Jsurf (A_per_m)

$7.0000 e-001$

$6.5000 e-001$

$6.0000 e-001$

$5.5000 e-001$

$5.0000 e-001$

$4.5000 e-001$

$4.0000 e-001$

$3.5000 e-001$

$3.0000 e-001$

$2.5000 e-001$

$2.0000 e-001$

$1.5000 e-001$

$1.0000 e-001$

$5.0000 e-002$

$0.0000 e+000$

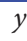

$y$

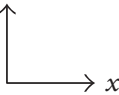

(d)

FIGURE 5: The simulated surface current distribution on $6 \times 6$ HIS array: (a) $0.55 \mathrm{GHz}$, (b) $0.60 \mathrm{GHz}$, (c) $0.65 \mathrm{GHz}$, and (d) $0.70 \mathrm{GHz}$.

two utmost edges in the $\pm y$ direction, meaning that the characteristics and effect of HIS are not obvious at these areas. Therefore, these two edges can be removed, and the minimization to a $4 \times 6$ array becomes feasible. However, further reduction to $4 \times 5$ or $4 \times 4$ array is not practicable, since the current is strong at two utmost edges in the $\pm x$ direction especially in Figures 5(b) and 5(c). The above analysis indicates that the HIS reflector of this proposed antenna can be minimized to $4 \times 6$ array.

To validate the above prediction, HIS effect on antenna performance is investigated. The only varying parameter is the cell number of HIS reflector, that is, $6 \times 6,5 \times 6,4 \times 6,4 \times$ 5 , and $4 \times 4$ arrays as listed in Figures 6 and 7 . The following phenomena are observed.
(1) When the reflector size is reduced from $6 \times 6$ to $5 \times$ 6 and further to $4 \times 6$, the impedance bandwidth becomes wider as shown in Figure 6(a), and the highest operating frequency shifts from $0.795 \mathrm{GHz}$ to $0.84 \mathrm{GHz}$. In Figure 6(b), antenna gain within $0.52-0.75 \mathrm{GHz}$ slightly decreases due to the smaller reflector ground. Nevertheless, this reduction results in higher gain above $0.75 \mathrm{GHz}$ due to the improved impedance matching. Additionally, both of the $E$ - and $H$ plane radiation patterns in Figure 7 remain the same in the directive radiation and increase slightly in the back radiation (when $\theta=180^{\circ}$ ) with reduced reflector.

(2) When the reflector is further reduced to $4 \times 5$ or $4 \times 4$, it deteriorates the antenna impedance matching as shown in Figure 6(a), because the number of HIS arrays is 


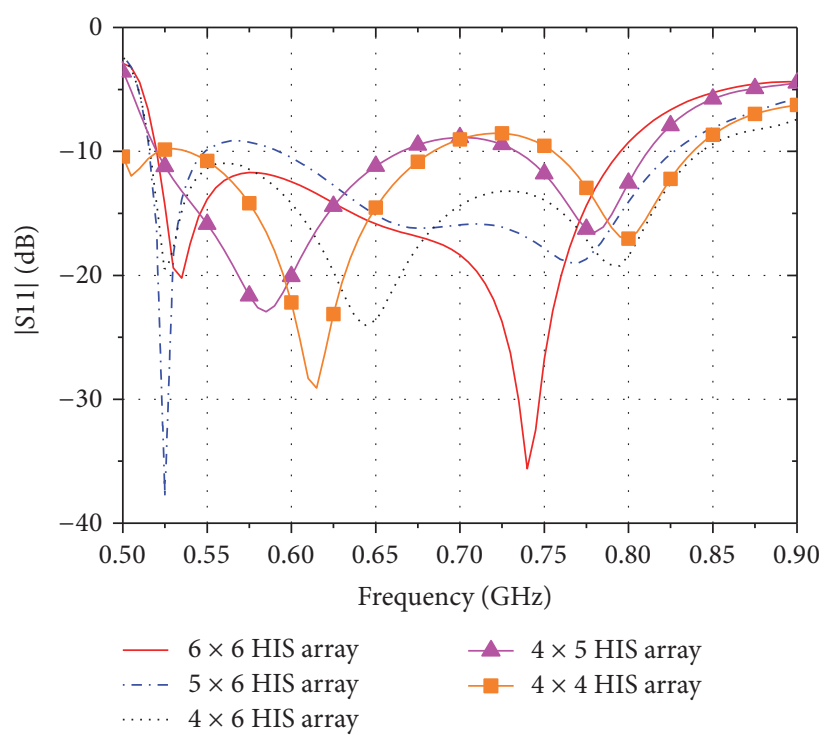

(a)

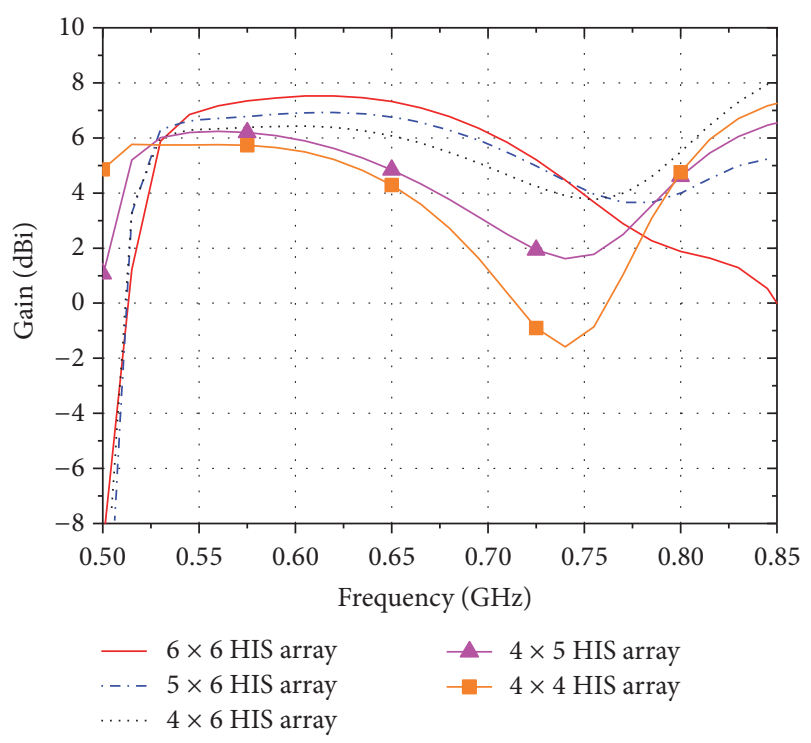

(b)

FIGURE 6: The effect of HIS array size to the antenna: (a) impedance matching and (b) gain.

too small to support the multiple resonances generated by the bow tie antenna as shown in Figure 5. It incurs a sharp drop in antenna gain above $0.65 \mathrm{GHz}$; additionally, this reduction will seriously affect the radiation patterns as illustrated in Figure 7. The HIS surface wave suppression ability becomes worse, as radiation becomes stronger at $\theta= \pm 90^{\circ}$ in the $E$ plane; the backside radiation also increases in both $E$ - and $H$-planes. Even worse, at higher operating frequency, the radiation pattern appears to have split up as in Figures $7(d)$ and $7(\mathrm{~h})$, the maximum radiation is no longer in the $+z$ direction (when $\theta=0^{\circ}$ ) but changed to two peaks radiation at $\theta= \pm 40^{\circ}$ for $4 \times 5$ and $\theta= \pm 60^{\circ}$ for $4 \times 4$ array, respectively. This phenomenon is well explained in [17]. Meanwhile, as indicated in Figure 7, the impact of reflector size to the antenna cross-polarization radiation is not obvious, which is at least more than $20 \mathrm{~dB}$ for most of the above cases.

In summary, the above analysis agrees well with the prediction from current distribution; that is, the HIS can be minimized to $4 \times 6$ array (or $0.55 \lambda_{L} \times 0.83 \lambda_{L} \times 0.076 \lambda_{L}$ referred to $f_{L}=0.52 \mathrm{GHz}$ ), without affecting the antenna performances such as bandwidth, gain, and directive radiation.

\section{Wideband Substrate-Less HIS}

The above Section 2 shows antenna with minimized size, whereas the bandwidth can be further improved. From (1) and (4), the HIS bandwidth can be improved either by increasing $L$ or decreasing $C$; however, to maintain the lowprofile characteristics, air-gap HIS $\left(\varepsilon_{r 1}=\varepsilon_{r 2}=1\right)$ is investigated in this section.

As shown in Figure 8(a), the unit cell is formed by air gap without any dielectric substrate like Teflon; that is, it is substrate-less. As compared in Figure 8(b), when the HIS substrate is changed from Teflon to air while keeping all other parameters, the resonant frequency shifts to higher frequency, and the bandgap becomes wider. Therefore, the following steps are carried on to update the HIS unit cell structure. Firstly, the HIS shorting via is changed from M10 screw to $r=7 \mathrm{~mm}$, while keeping the same height ( $h$ $=30 \mathrm{~mm}$ ), as well as maintaining the frequency response. Secondly, to shift down the resonant frequency, following the trend summarized in Table 1, the HIS patch width is increased to $w=80 \mathrm{~mm}$, and the gap between two adjacent patches reduces to $g=5 \mathrm{~mm}$, respectively. The reflection response of substrate-less HIS is then almost equal to the substrate one as shown in Figure 8(b).

This $4 \times 6$ air-gap HIS array is employed as the reflector, with $3 \mathrm{D}$ view in Figure $8(\mathrm{c})$. In cross-sectional view in Figure $8(\mathrm{~d})$, the antenna is located on top of spacer head with height $h_{3}=2.2 \mathrm{~mm}$. Other parameters keep the same as in Section 2, that is, top HIS brass patches with $h_{1}=0.5 \mathrm{~mm}$ and aluminum ground with $h_{2}=6 \mathrm{~mm}$. Finally, the overall size of this antenna is $340 \times 510 \times 40.3 \mathrm{~mm}^{3}$. Simulated results are compared with measurement curves in Section 4.

\section{Measurement Results and Discussions}

Based on the above analysis, both of the antennas on substrate and substrate-less HIS are fabricated and shown in Figure 9. In Figure $9(\mathrm{a})$, the $6 \times 6 \mathrm{HIS}$ array is assembled by two parts: the center part of $4 \times 6$ array and two $1 \times 6$ rows added at two edges. Therefore, both of the two antennas with $6 \times 6$ and $4 \times 6$ HIS reflectors can be measured. In Figure 9(b), nylon spacers are added in assembly at four corners of each brass patches to ensure the flatness.

4.1. Bowtie Antenna with Dielectric-Substrate HIS. Figure 10 shows the simulated and measured results of the bow 

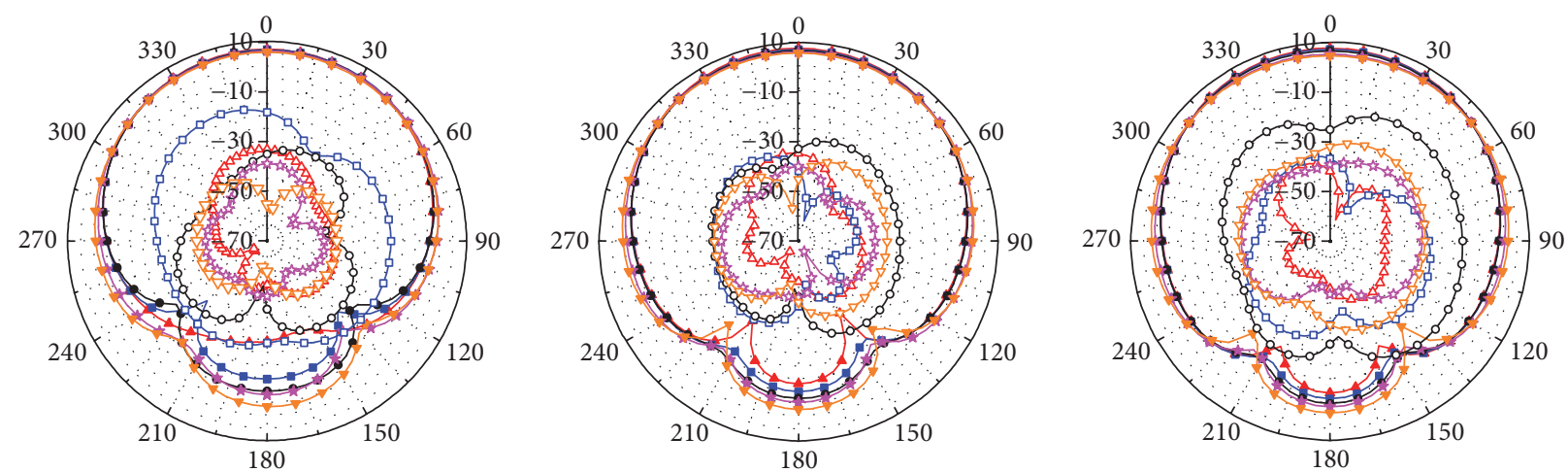

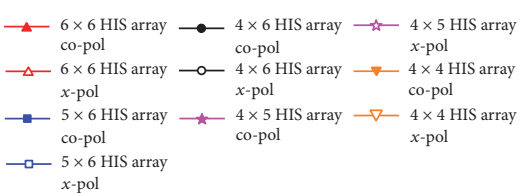

(a) $0.55 \mathrm{GHz}$ ( $E$-plane)
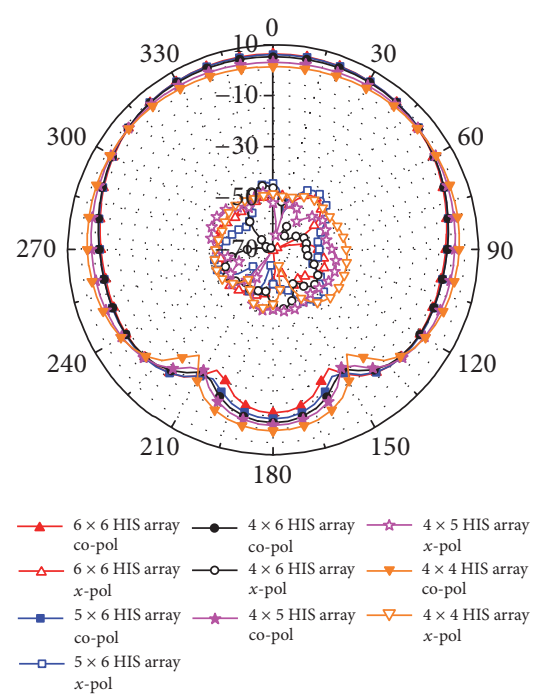

(d) $0.70 \mathrm{GHz}$ (E-plane)

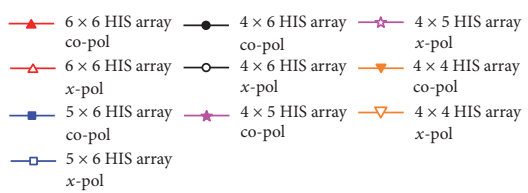

(b) $0.60 \mathrm{GHz}$ (E-plane)
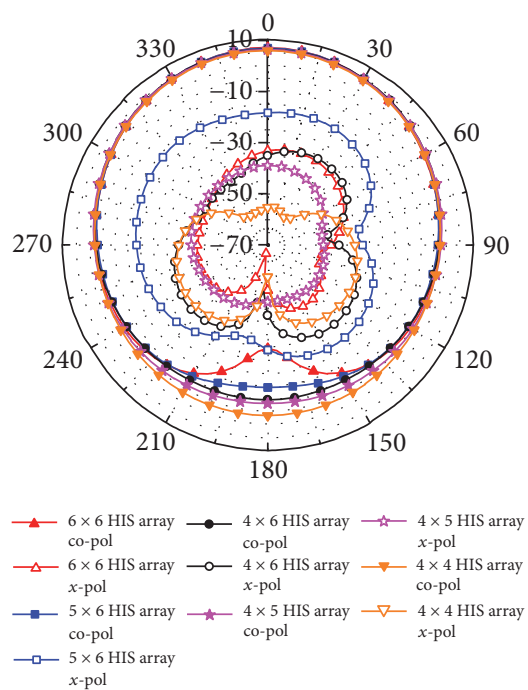

(e) $0.55 \mathrm{GHz}(H$-plane $)$

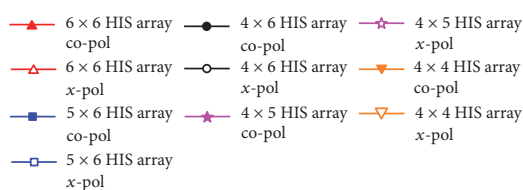

(c) $0.65 \mathrm{GHz}$ (E-plane)
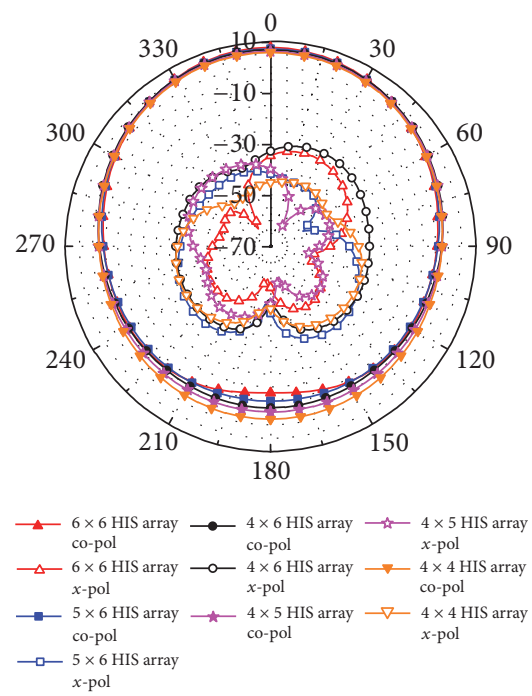

(f) $0.60 \mathrm{GHz}(H$-plane)

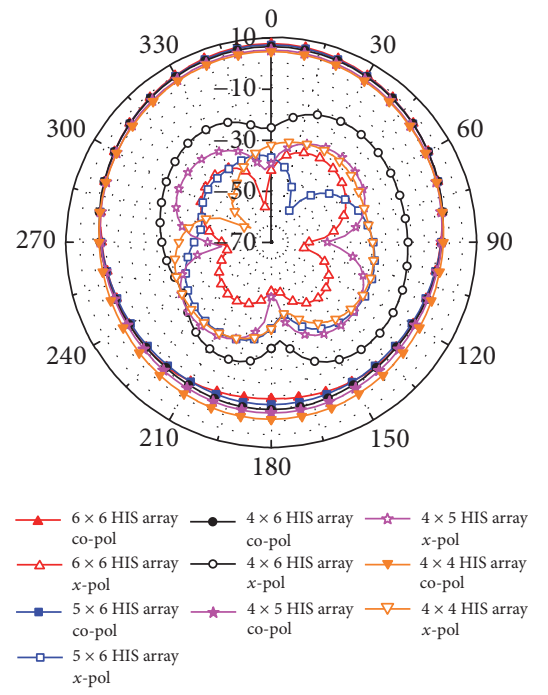

(g) $0.65 \mathrm{GHz}(H$-plane $)$

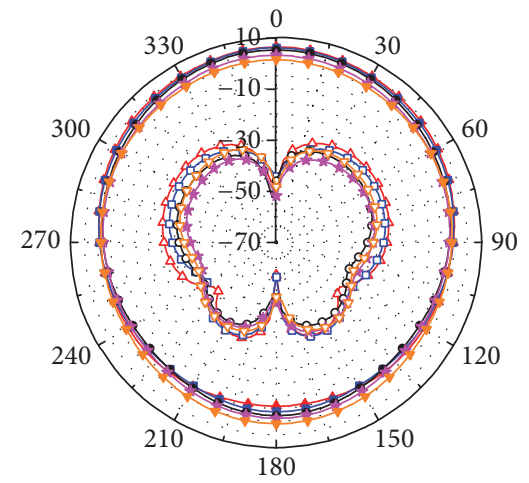

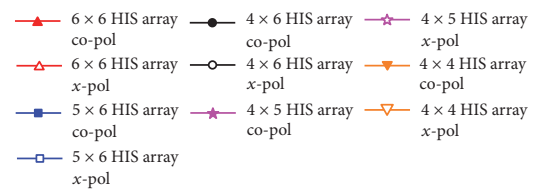

(h) $0.70 \mathrm{GHz}$ (H-plane)

FIGURE 7: Effect of HIS array size to the radiation patterns on $E(z-x)$ and $H(z-y)$ planes at four frequency points: $0.55 \mathrm{GHz}, 0.60 \mathrm{GHz}$, $0.65 \mathrm{GHz}$, and $0.70 \mathrm{GHz}$. 


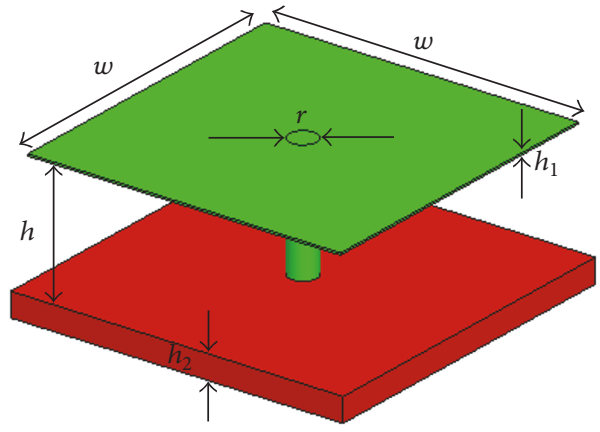

(a)

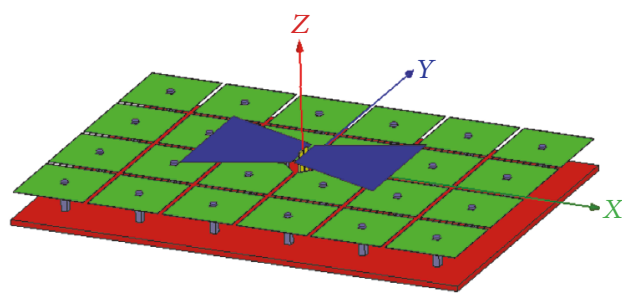

(c)

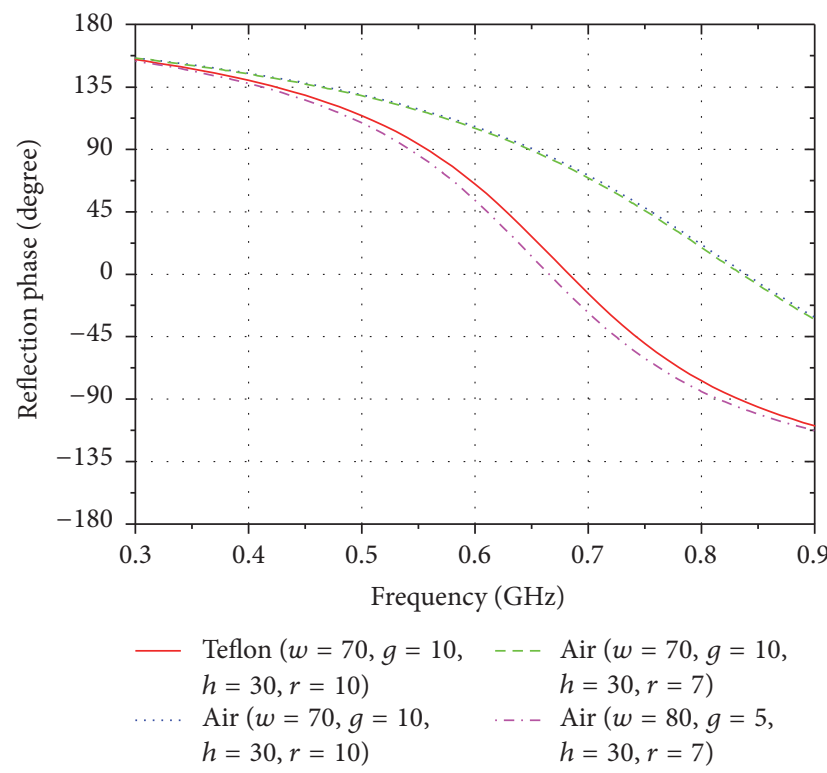

(b)

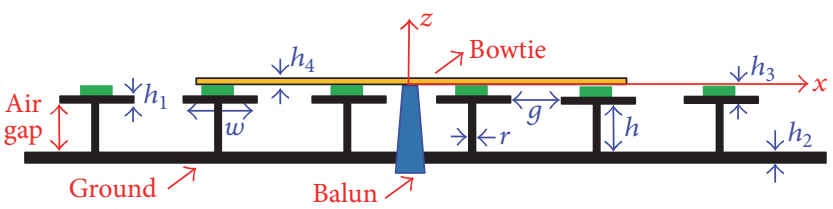

(d)

Figure 8: The low-profile bow tie antenna on substrate-less HIS: (a) substrate-less HIS unit cell, (b) reflection phase response, (c) 3D view, and (d) cross-sectional view.

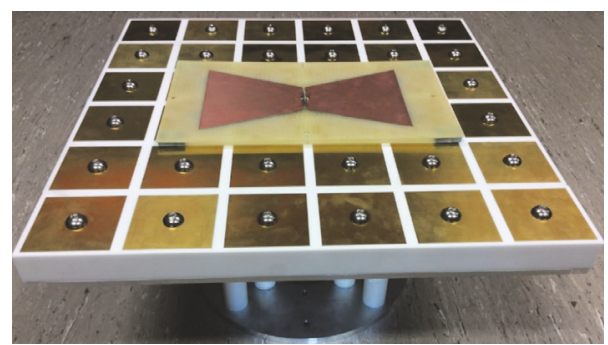

(a)

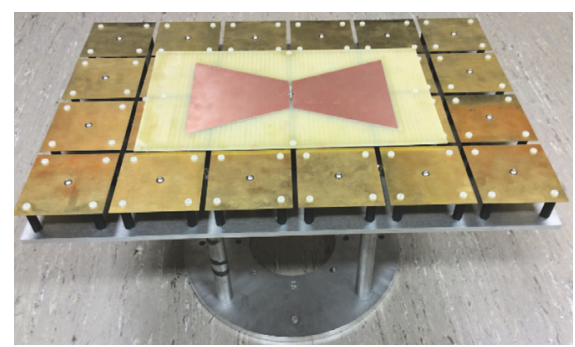

(b)

FIGURE 9: The fabricated prototype of low-profile bow tie antennas: (a) with dielectric-substrate HIS and (b) with substrate-less HIS.

tie antennas with $6 \times 6$ and $4 \times 6$ HIS arrays. For the case of $6 \times 6$ array, the simulated $10 \mathrm{~dB}$ return-loss bandwidth is $0.52-0.79 \mathrm{GHz}$ or a fractional bandwidth of $41 \%$, whereas the measured one is slightly narrower, about $33 \%$ of $0.55-0.77 \mathrm{GHz}$. On the other hand, the antenna with a minimized $4 \times 6$ array has wider impedance bandwidth, up to $47 \%$ of $0.52-0.84 \mathrm{GHz}$ in simulation and $36 \%$ of $0.54-0.78 \mathrm{GHz}$ in measurement. The measured center frequency of both antennas is at $0.66 \mathrm{GHz}$. Correspondingly, based on measured results, the overall electrical sizes are $0.88 \lambda_{L} \times 0.88 \lambda_{L} \times 0.079 \lambda_{L}$ (where $f_{L}=0.55 \mathrm{GHz}, 480 \times 480 \times$ $\left.43.1 \mathrm{~mm}^{3}\right)$ for the $6 \times 6$ array and $0.57 \lambda_{L} \times 0.86 \lambda_{L} \times 0.078 \lambda_{L}$ (where $f_{L}=0.54 \mathrm{GHz}, 320 \times 480 \times 43.1 \mathrm{~mm}^{3}$ ) for the $4 \times 6$ array, respectively.

The antenna gain is plotted in Figure 10(b), the antenna gain of the $6 \times 6$ array is higher than that of the $4 \times 6$ array, because of the larger reflector size. The maximum antenna gain is $5.6 \mathrm{dBi}$ for the $6 \times 6$ array and $5.1 \mathrm{dBi}$ for the $4 \times 6$ array.

Because of the setup limitation in our anechoic chamber, only the front side $\left(\theta=0^{\circ} \pm 90^{\circ}\right)$ can be measured. Figures 11 and 12 present the normalized radiation patterns in both $E$ - $(z-$ $x)$ and $H-(z-y)$ planes. Good agreement is achieved between simulated and measured copolarization results. Generally, the 


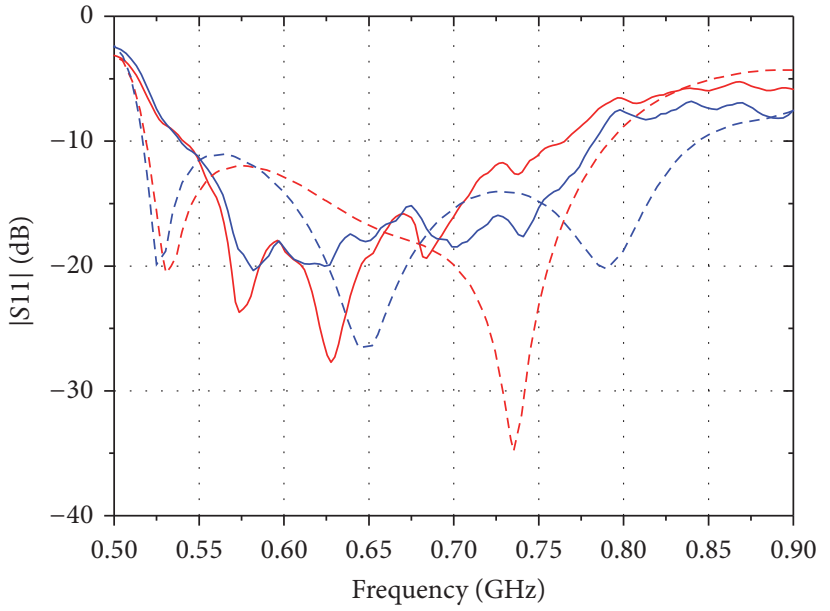

$\begin{array}{lll}\text { Measured }(6 \times 6) & --- \text { Simulated }(6 \times 6) \\ \text { Measured }(4 \times 6) & --- & \text { Simulated }(4 \times 6)\end{array}$

(a)

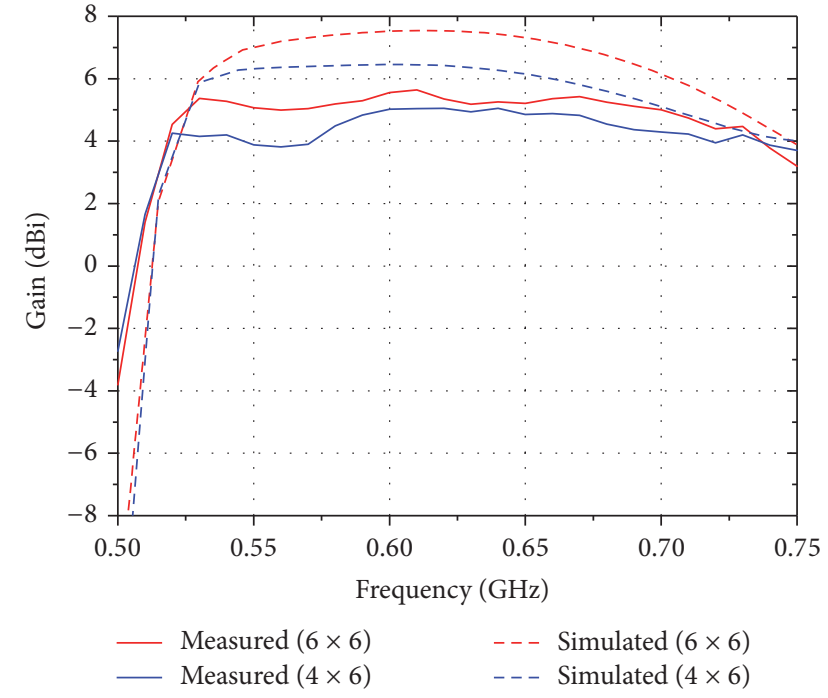

(b)

FIgURE 10: The simulated and measured results of the antenna in Figure 9(a): (a) return loss and (b) antenna gain.

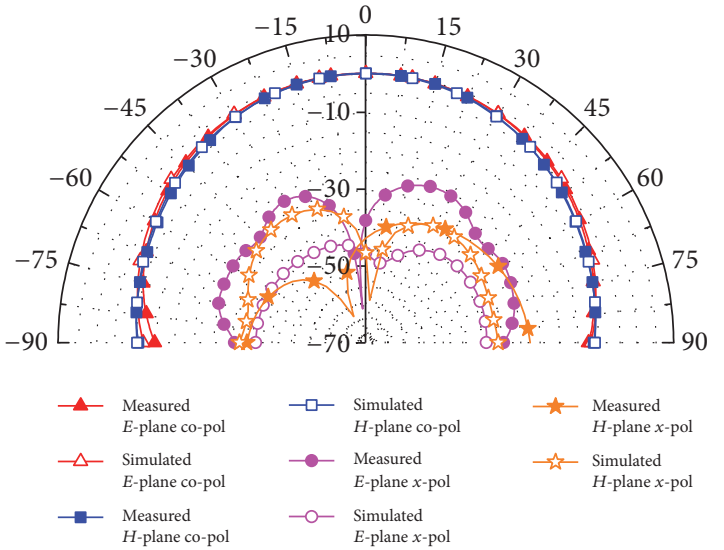

(a)

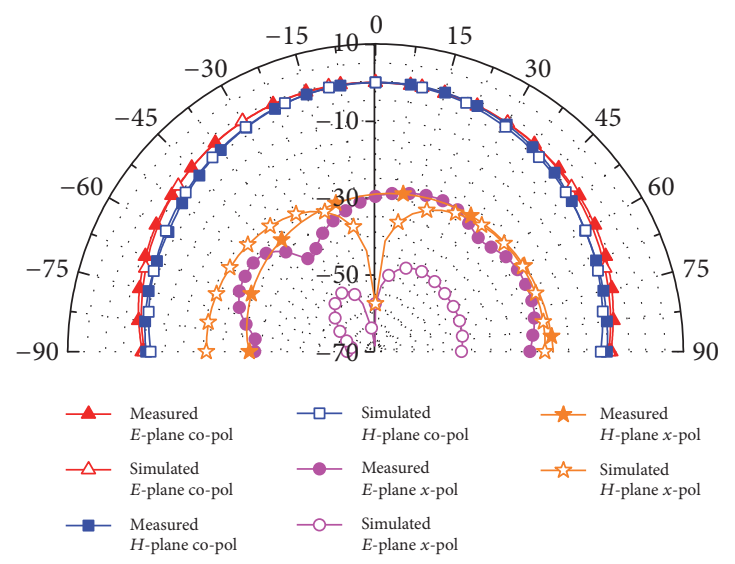

(c)

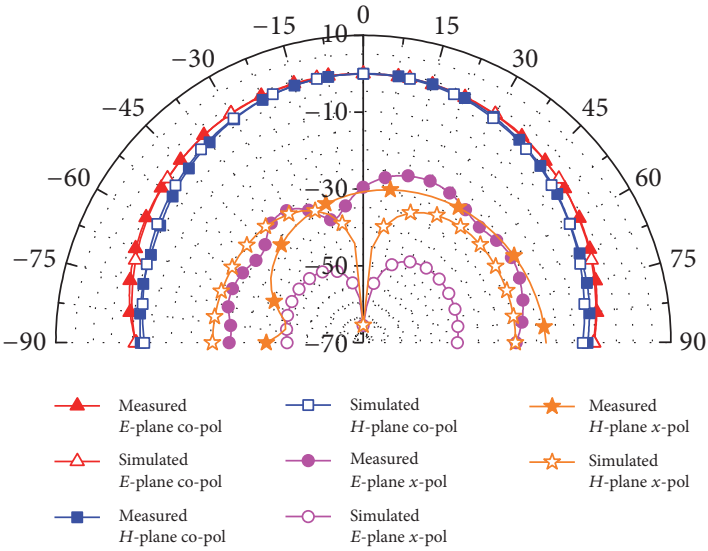

(b)

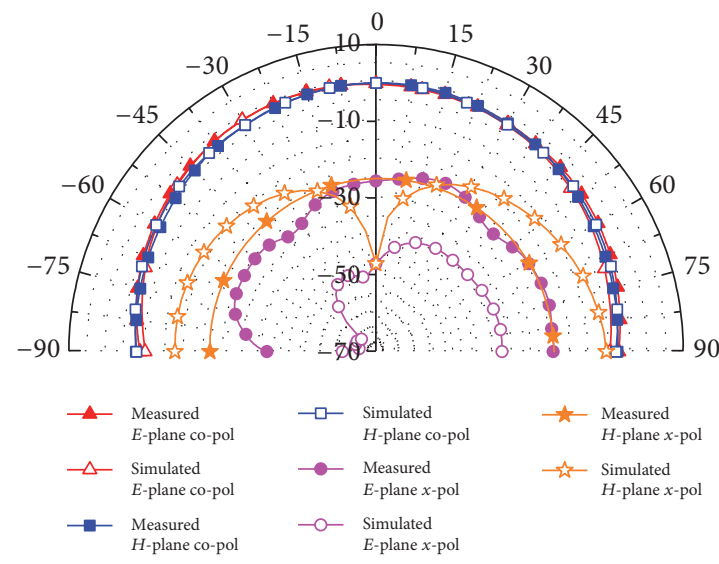

(d)

FIGURE 11: The simulated and measured normalized radiation patterns of the antenna in Figure 9 (a) with $6 \times 6 \mathrm{HIS}$ array: (a) $0.55 \mathrm{GHz}$, (b) $0.60 \mathrm{GHz}$, (c) $0.65 \mathrm{GHz}$, and (d) $0.70 \mathrm{GHz}$. 


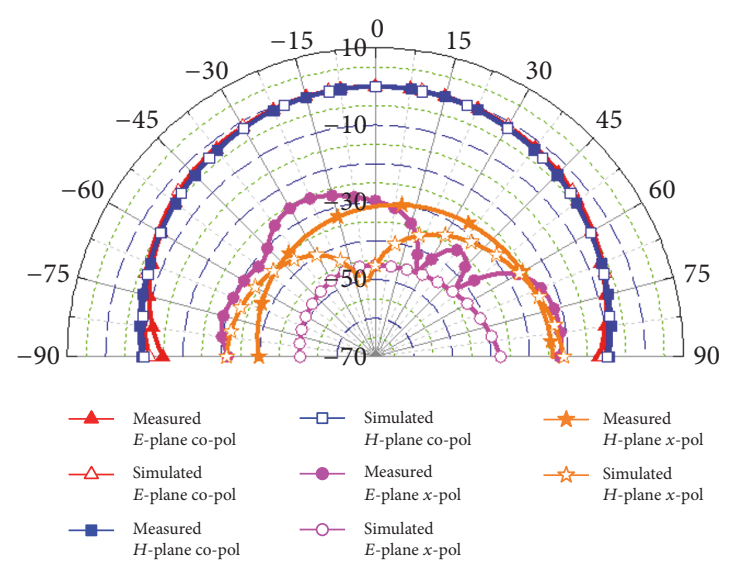

(a)

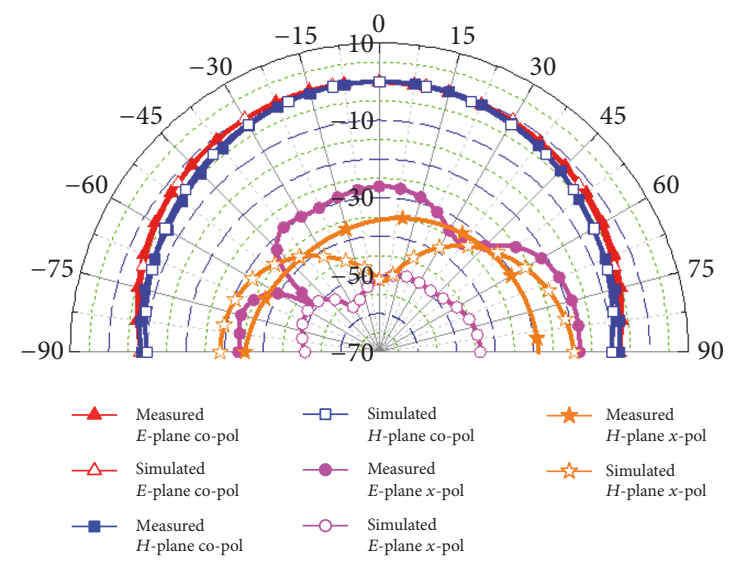

(c)

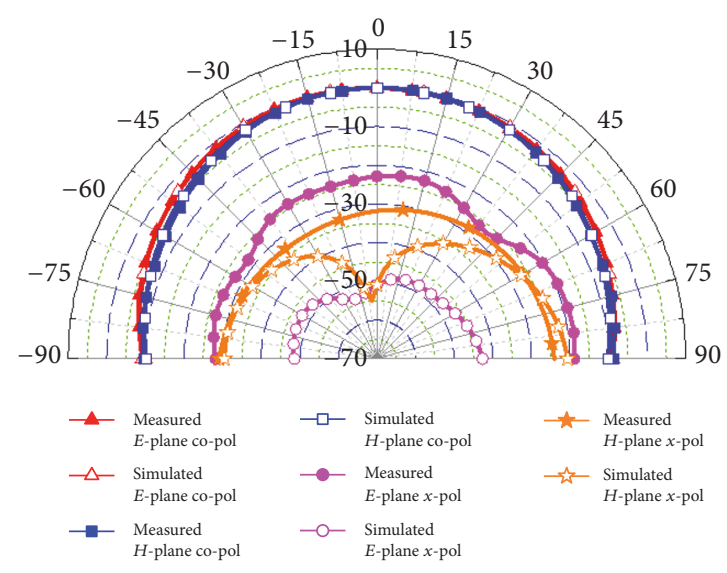

(b)

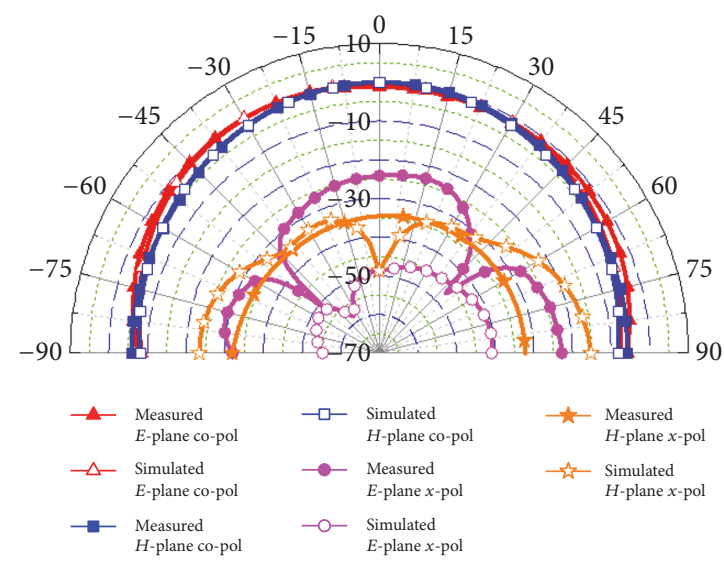

(d)

FIGURE 12: The simulated and measured normalized radiation patterns of the antenna in Figure 9 (a) with $4 \times 6 \mathrm{HIS}$ array: (a) $0.55 \mathrm{GHz}$, (b) $0.60 \mathrm{GHz}$, (c) $0.65 \mathrm{GHz}$, and (d) $0.70 \mathrm{GHz}$.

measured cross-polarization value is slightly higher than the simulated ones, but also with at least $22 \mathrm{~dB}$ for both of the 6 $\times 6$ and $4 \times 6$ array. Additionally, in Figure 12, although the reflector is minimized to $4 \times 6$, it does not affect the radiation patterns, that is, directive patterns with maximum radiation at $\theta=0^{\circ}$. This measurement verifies the analysis as discussed in Section 2.3.

4.2. Bow Tie Antenna with Substrate-Less HIS. For the substrate-less antenna prototype in Figure 9(b), as shown in Figure 13(a), the simulated $\left|S_{11}\right|$ is $0.5-0.9 \mathrm{GHz}$, or $57 \%$ to the center frequency of $0.7 \mathrm{GHz}$, while the measured one is $0.5-0.85 \mathrm{GHz}$, about $52 \%$ to the center frequency at $0.675 \mathrm{GHz}$. Compared to antennas in Section 4.1, it is with wider bandwidth.

The antenna gain is shown in Figure 13(b). The measured gain is slightly lower than the simulated one, and it varies from $3.7 \mathrm{dBi}$ to $6 \mathrm{dBi}$ covering the entire operation band. Figure 14 shows the normalized radiation patterns at four frequencies, that is, $0.55 \mathrm{GHz}, 0.65 \mathrm{GHz}, 0.75 \mathrm{GHz}$, and $0.85 \mathrm{GHz}$. The directive copolarization radiation is observed in both of the simulated and measured results, and the maximum radiation is at $\theta=0^{\circ}$. It also achieves more than $20 \mathrm{~dB}$ cross-polarization, with measured $E$-plane results agreeing well with simulation while $H$-plane result is higher than simulation. The performances of the proposed and other reported bow tie antennas on HIS are summarized and compared in Table 2.

\section{Conclusion}

This paper presents minimized low-profile antenna by using HIS ground reflector. A substrate-less HIS is proposed to achieve wide bandwidth up to $52 \%$. Meanwhile, the effect and limitation of ground reflector are analyzed, and minimized reflector size is obtained without affecting antenna performance.

\section{Conflicts of Interest}

The author declare that there are no conflicts of interest regarding the publication of this paper. 


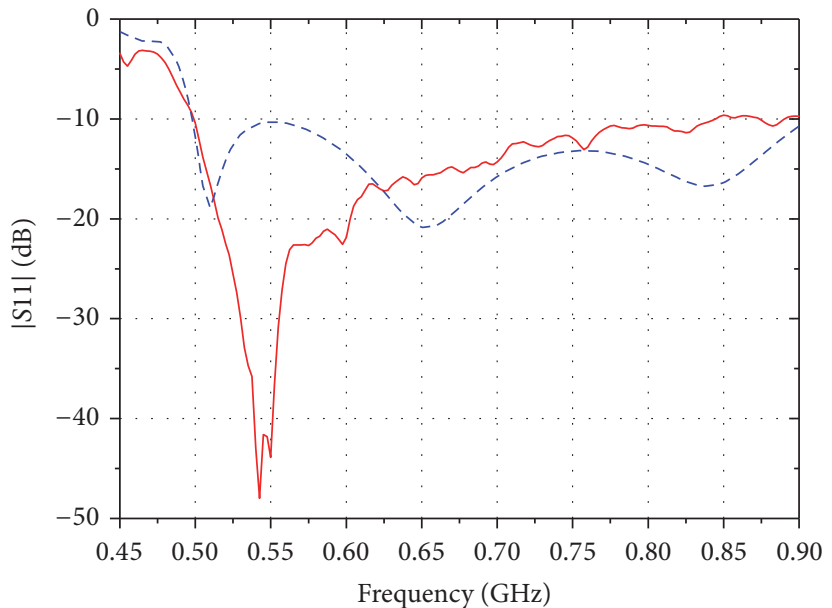

- Measured
-- Simulated

(a)

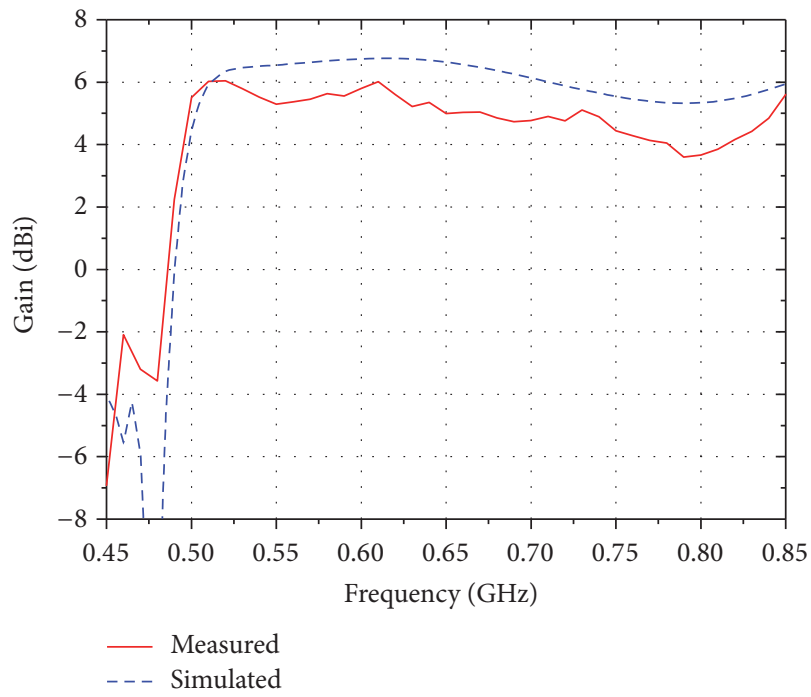

(b)

FIGURE 13: The simulated and measured results of the antenna in Figure 9(b): (a) return loss and (b) antenna gain.

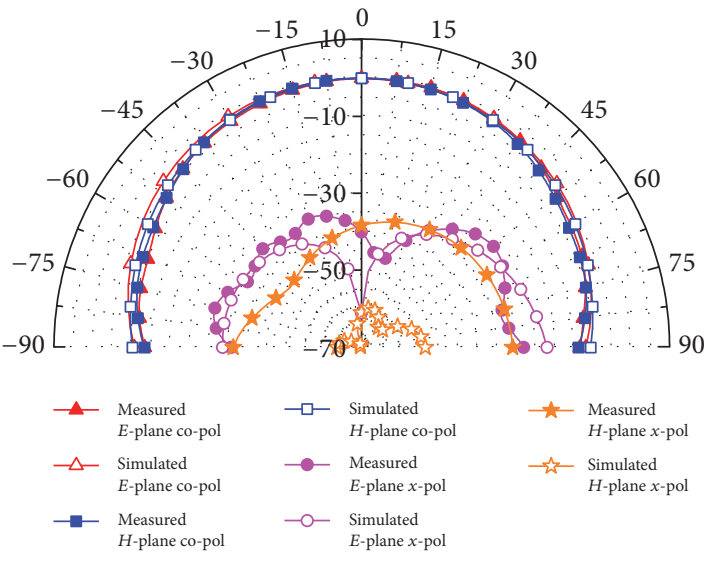

(a)

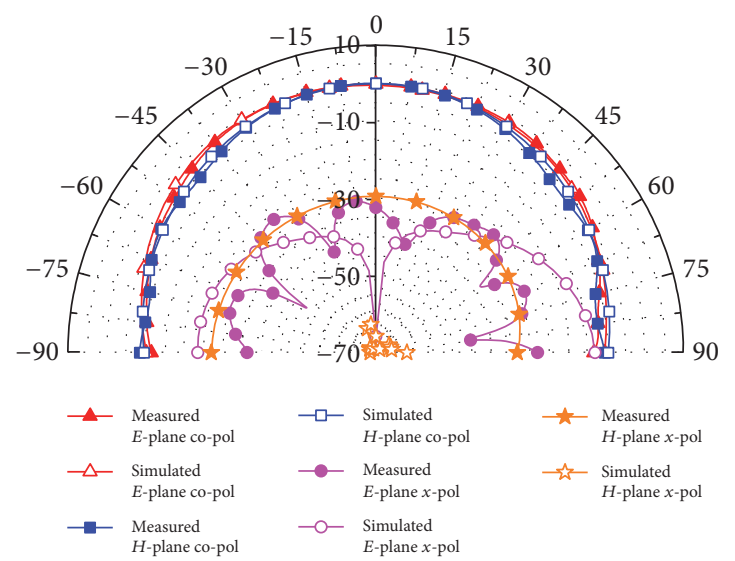

(c)

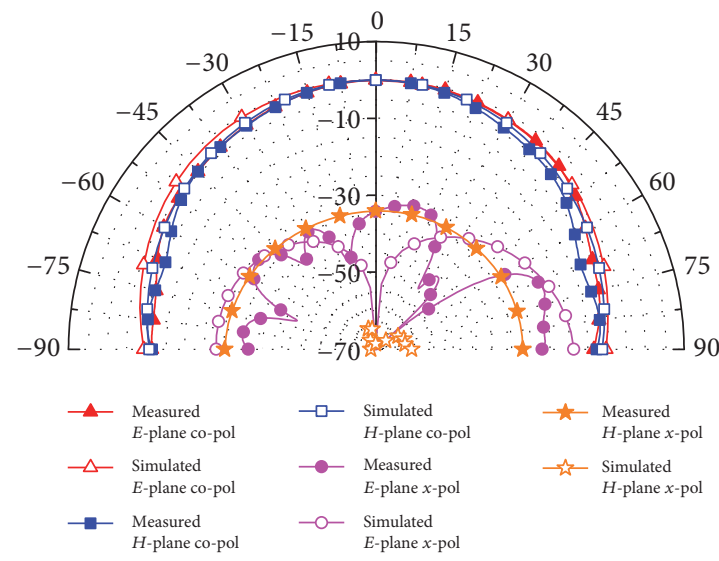

(b)
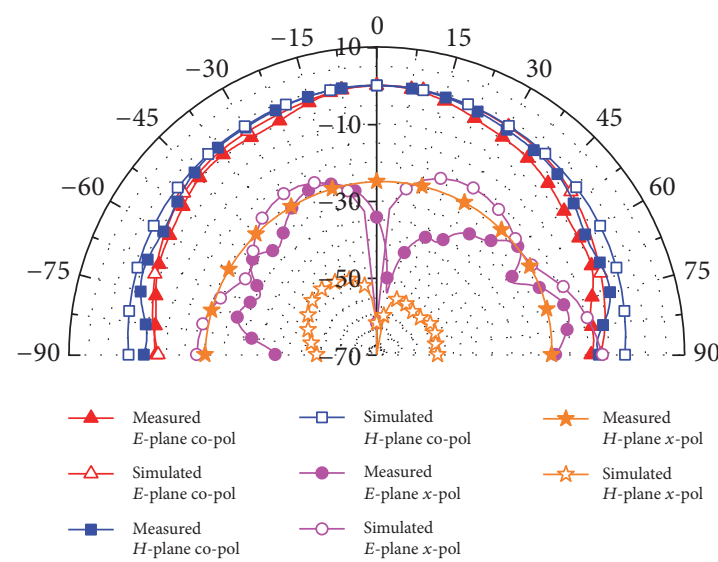

(d)

FIGURE 14: The simulated and measured normalized radiation patterns of the antenna in Figure 9(b): (a) $0.55 \mathrm{GHz}$, (b) $0.65 \mathrm{GHz}$, (c) $0.75 \mathrm{GHz}$, and (d) $0.85 \mathrm{GHz}$. 
TABLE 2: Performance summary and comparison of HIS antennas.

\begin{tabular}{lccccc}
\hline & Substrate & Ground size & Thickness & Max gain & Bandwidth \\
\hline This work & & & & & \\
$\quad$ Antenna on $4 \times 6$ substrate-less HIS & Air-gap & $0.57 \lambda_{L} \times 0.85 \lambda_{L}$ & $0.067 \lambda_{L}$ & $6.0 \mathrm{dBi}$ & $(0.5-0.85) \mathrm{GHz} 52 \%$ \\
$\quad$ Antenna on $4 \times 6$ dielectric-substrate HIS & Teflon & $0.57 \lambda_{L} \times 0.86 \lambda_{L}$ & $0.078 \lambda_{L}$ & $5.1 \mathrm{dBi}$ & $(0.54-0.78) \mathrm{GHz} 36 \%$ \\
{$[13]$} & RT/duroid 5880 & $0.86 \lambda_{L} \times 0.86 \lambda_{L}$ & $0.067 \lambda_{L}$ & $8.7 \mathrm{dBi}$ & $(4.3-5) \mathrm{GHz} 15 \%$ \\
{$[14]$} & RT/duroid 5880 & $1.25 \lambda_{L} \times 1.25 \lambda_{L}$ & $0.06 \lambda_{L}$ & $6.0 \mathrm{dBi}$ & $(1.06-1.5) \mathrm{GHz} 34 \%$ \\
{$[15]$} & FR4 & $1.24 \lambda_{L} \times 1.24 \lambda_{L}$ & $0.05 \lambda_{L}$ & $9.4 \mathrm{dBi}$ & $(3.2-5) \mathrm{GHz} 44 \%$ \\
{$[16]$} & RT/duroid 5880 & $0.67 \lambda_{L} \times 0.84 \lambda_{L}$ & $0.102 \lambda_{L}$ & $6.9 \mathrm{dBi}$ & $(2-3.2) \mathrm{GHz} 46 \%$ \\
\hline
\end{tabular}

\section{References}

[1] D. Sievenpiper, L. Zhang, R. F. J. Broas, N. G. Alexöpolous, and E. Yablonovitch, "High-impedance electromagnetic surfaces with a forbidden frequency band," IEEE Transactions on Microwave Theory and Techniques, vol. 47, no. 11, pp. 2059-2074, 1999.

[2] R. Coccioli, F.-R. Yang, K.-P. Ma, and T. Itoh, "Aperture-coupled patch antenna on UC-PBG substrate," IEEE Transactions on Microwave Theory and Techniques, vol. 47, no. 11, pp. 2123-2130, 1999.

[3] J. J. H. Wang and V. K. Tripp, "Design of multioctave spiralmode microstrip antennas," IEEE Transactions on Antennas \& Propagation, pp. 332-335, 1991.

[4] H. Nakano, K. Kikkawa, Y. Iitsuka, and J. Yamauchi, "Equiangular spiral antenna backed by a shallow cavity with absorbing strips," IEEE Transactions on Antennas and Propagation, vol. 56, no. 8, pp. 2742-2747, 2008.

[5] H. Nakano, K. Nogami, S. Arai, H. Mimaki, and J. Yamauchi, "A Spiral Antenna Backed by a Conducting Plane Reflector," IEEE Transactions on Antennas and Propagation, vol. 34, no. 6, pp. 791-796, 1986.

[6] R. Li, B. Pan, A. N. Traille, J. Papapolymerou, J. Laskar, and M. M. Tentzeris, "Development of a cavity-backed broadband circularly polarized slot/strip loop antenna with a simple feeding structure," IEEE Transactions on Antennas and Propagation, vol. 56, no. 2, pp. 312-318, 2008.

[7] R. Gonzalo, P. De Maagt, and M. Sorolla, "Enhanced patchantenna performance by suppressing surface waves using photonic-bandgap substrates," IEEE Transactions on Microwave Theory and Techniques, vol. 47, no. 11, pp. 2131-2138, 1999.

[8] N. H. Chamok, M. Ali, T. K. Anthony, and S. J. Weiss, "UltraThin UHF Broadband Antenna on a Non-Uniform Aperiodic (NUA) MetaSurface," IEEE Antennas and Propagation Magazine, vol. 57, no. 2, pp. 167-180, 2015.

[9] X. Zhang, Z. Teng, Z. Liu, and B. Li, "A dual band patch antenna with a pinwheel-shaped slots EBG substrate," International Journal of Antennas and Propagation, vol. 2015, Article ID 815751, 2015.

[10] R. Chantalat, C. Menudier, M. Thevenot, T. Monediere, E. Arnaud, and P. Dumon, "Enhanced EBG resonator antenna as feed of a reflector antenna in the Ka band," IEEE Antennas and Wireless Propagation Letters, vol. 7, pp. 349-353, 2008.

[11] A. Vallecchi, J. R. De Luis, F. Capolino, and F. De Flaviis, "Low profile fully planar folded dipole antenna on a high impedance surface," IEEE Transactions on Antennas and Propagation, vol. 60, no. 1, pp. 51-62, 2012.

[12] J. Wu and K. Sarabandi, "Reactive impedance surface TM mode slow wave for patch antenna miniaturization [AMTA corner],"
IEEE Antennas and Propagation Magazine, vol. 56, no. 6, pp. 279-293, 2014.

[13] P. Deo, A. Mehta, D. Mirshekar-Syahkal, P. J. Massey, and H. Nakano, "Thickness reduction and performance enhancement of steerable square loop antenna using hybrid high impedance surface," IEEE Transactions on Antennas and Propagation, vol. 58, no. 5, pp. 1477-1485, 2010.

[14] S. R. Best and D. L. Hanna, "Design of a broadband dipole in close proximity to an EBG ground plane," IEEE Antennas and Propagation Magazine, vol. 50, no. 6, pp. 52-64, 2008.

[15] A. Thior, A. C. Lepage, and X. Begaud, "Low profile, directive and ultra wideband antenna on a high impedance surface," in Proceedings of the 3rd European Conference on Antennas and Propagation, EuCAP 2009, pp. 3222-3226, Berlin, Germany, March 2009.

[16] Y. Liu, K. M. Luk, and H. Yin, "Bowtie patch antenna with electric dipole on a HIS substrate," in Proceedings of the International Conference on Microwave and Millimeter Wave Technology (ICMMT '10), pp. 278-280, Chengdu, China, May 2010.

[17] C. Joshi, A. C. Lepage, J. Sarrazin, and X. Begaud, "Enhanced broadside gain of an ultrawideband diamond dipole antenna using a hybrid reflector," IEEE Transactions on Antennas and Propagation, vol. 64, no. 7, pp. 3269-3274, 2016. 


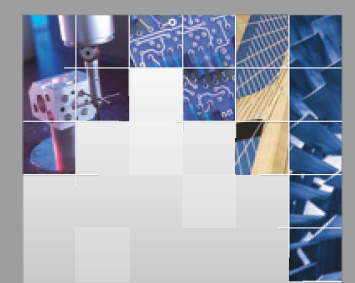

\section{Enfincering}
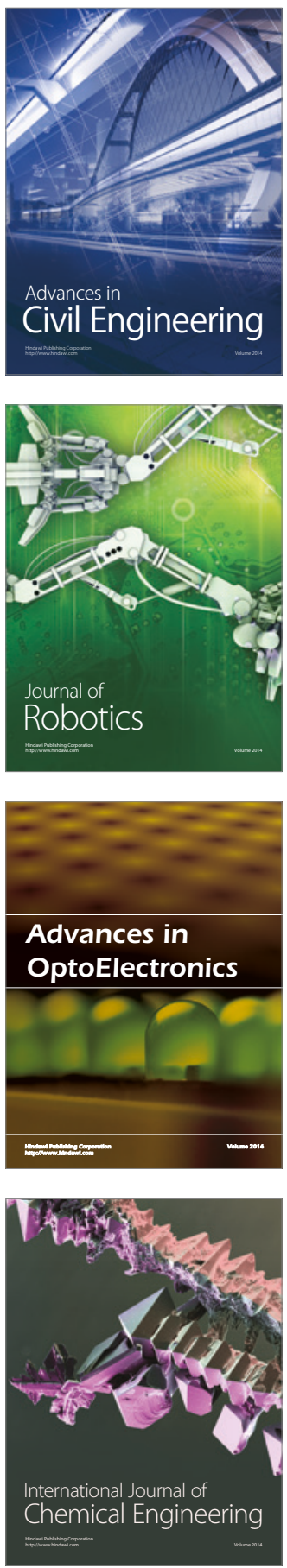

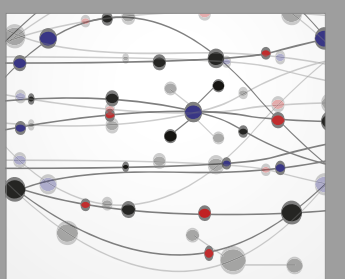

The Scientific World Journal

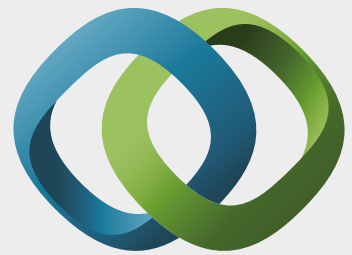

\section{Hindawi}

Submit your manuscripts at

https://www.hindawi.com
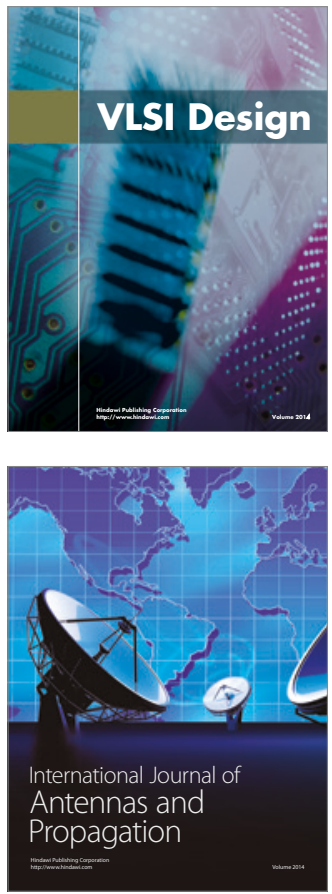

\section{Rotating}

Machinery
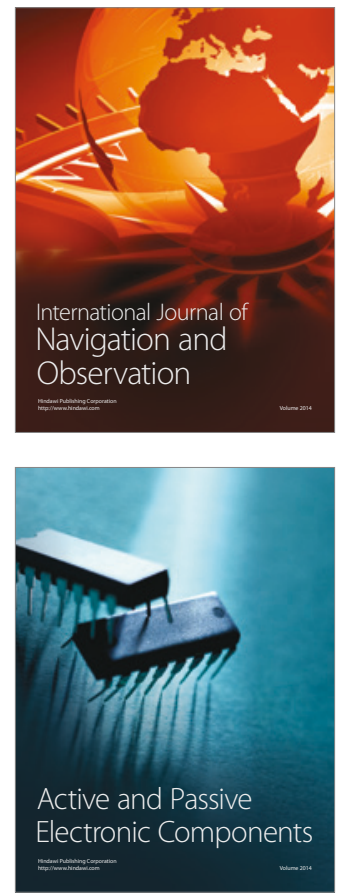
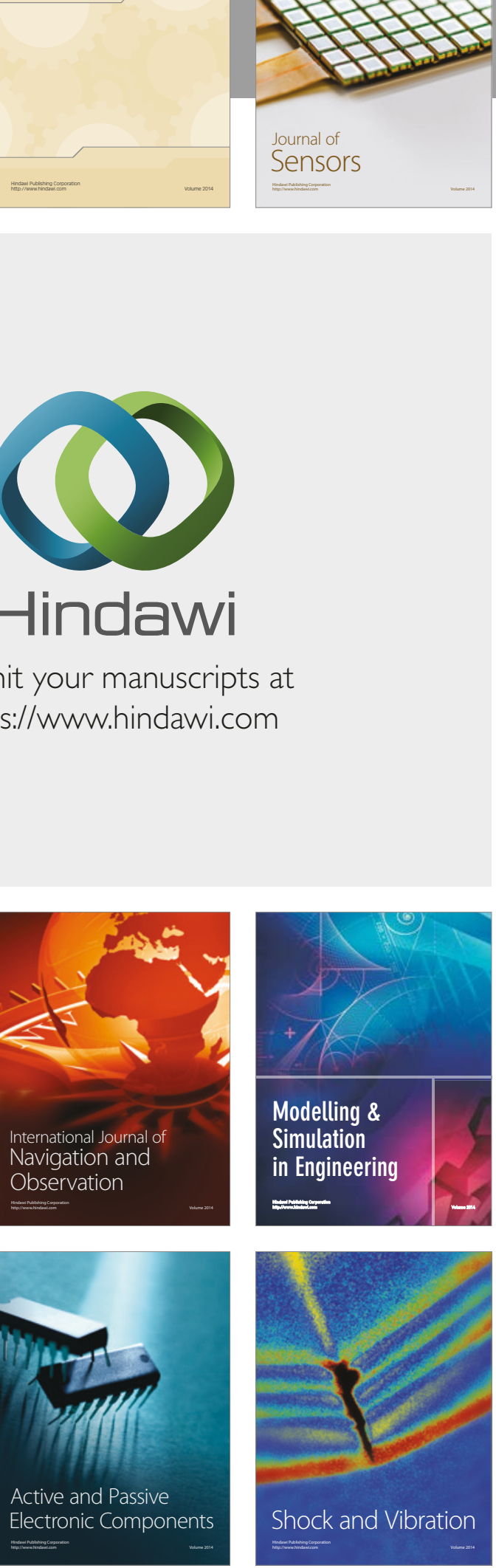
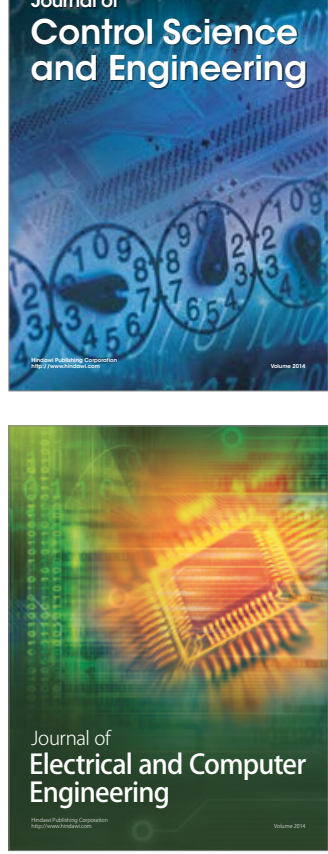

Distributed

Journal of

Control Science

and Engineering
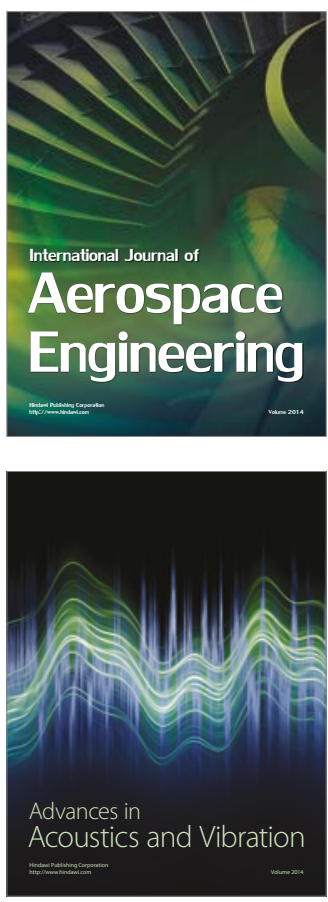

Sensor Networks 